\title{
Correspondence
}

\section{A CRITICAL TABLE FOR SEXTANT CORRECTIONS}

SIR,

Reference the article under the above title by A. N. Black in the October issue of the Journal (Vol. 2, No. 4, p. 342), Mr. Black's correction of the equation for the centring error as actually measured is accepted, but I would like to remark that there are two cases to be considered. First, the case of the owner of a sextant with a certificate made out in the present form which he wishes to convert to critical form; second, the case of a testing laboratory, such as the N.P.L., concerned with the issue of new certificates. Mr. Black's article covers the first case only. The equation is not essential to case 2 for it is understood that the method normally employed to obtain the errors at fixed points could equally well be used to read off the angles at the critical error points. As Mr. Black suggests, it would probably be perfectly acceptable to have the critical points given at whole degrees.

Yours truly,

J. P. G. WORLlEdGE.

\section{THE ACCURACY REQUIREMENTS OF AN EN-ROUTE AID}

SIR,

Recent meetings of the Institute have, to my mind, underlined the divergence of air navigators' opinions concerning the accuracy requirements of a modern en-route navigational aid. Views fall between two extremes:

(a) An en-route aid is unnecessary, provided that good coverage for homing exists at terminal points;

(b) Fast and high flying aircraft require as high a degree of fixing accuracy as possible.

A third view is that position determination is not, primarily, a requirement at all; the navigator needs to know, first and foremost, what to do and not where he is.

It must be extremely baffling for the instrument manufacturer to note this disparity of opinion. In an endeavour to reconcile the various viewpoints (an effort which may well lead to some controversy) will you permit me to advance some arguments in favour of a compromise solution?

Given that aids of high accuracy will always be required for special purposes (e.g. homing and control of aircraft, precision bombing, \&c.), there will nevertheless be vast areas of the Earth's surface, both for civil and military operations, where this high precision cannot be efficiently employed. In such areas, an optimum threshold figure of the order of ten nautical miles (95\% fixing error) has been suggested for position determination. ${ }^{2}$ It would appear that any advance on this is in the nature of a luxury; a competent navigator would certainly have no difficulty in undertaking a voyage using a reliable aid of this nature.

Taking first the question of fuel economy, it is known that on long flights a departure from the great circle route of 20 miles would have negligible effect on the fuel consumed. In any case, there is no sanctity in the great circle track; 
the minimal flight path is the ideal solution and even if this could be plotted with absolute certainty it would not be easy to justify a case for a highly accurate aid.

But the threshhold figure quoted may surely be further relaxed for high flying, fast, aircraft. While accurate wind finding is desirable at great heights (in the absence of reliable forecasts), it is difficult to see how accurate fixing alone would provide this. After all, the wind vector has two terminals, the air position and the fix; and errors in determining the former will in practice increase at great altitudes, where the faster aircraft types will operate. In the absence of accurate measures of course and airspeed, high fixing accuracy is of little value for wind finding purposes.

Finally, for emergency use, a knowledge of an accurate position at great height is of use only if the future track of the aircraft to ditching point (or point of forced landing) can be predicted within narrow limits. It seems unlikely that the pilot would be able to maintain his course and airspeed (or even a lower, constant, airspeed) accurately, and in any event the aircraft will be at the mercy of unknown, only roughly predictable, winds on the descent. Thus the inherent errors (which increase with altitude) associated with an emergency procedure permit a moderate accuracy to be tolerated at great heights.

Thus it appears that, as far as three main functions of a navigational aid are concerned (two more, that of computing a course to fly to an alternate, and that of recalculating the point of non-return have been discussed elsewhere ${ }^{2}$ ), a navigational aid of moderate precision, with, moreover, an error increasing with altitude, can be accepted; where other sources of error predominate, the effort required to improve the fixing accuracy beyond this threshhold will generally be out of proportion to the information gained. For en-route flying, a knowledge of his whereabouts, not his precise position, is sufficient to enable a competent navigator to discharge his duties safely, economically, and efficiently.

The fact that some navigational aids deteriorate in accuracy with altitude (examples are the pinpoint and astronomical navigation, the latter in view of higher aircraft speeds making determination of the vertical less accurate) does not in any way prejudice their claims for retention.

The deliberate acceptance of a moderate standard of accuracy for en-route flying will give the designer, and the author of navigational tables, a much greater latitude. Cheaper, simpler, less bulky, and probably more robust and reliable articles will be produced. Speedier methods of reduction, particularly in the astronomical field, may be developed. The navigator himself might wish to modify his techniques, using most probable positions more frequently, and averaging his track from a series of fixes. Surely a new outlook, sacrificing as it does neither safety nor economy, is a small price to pay for increased simplicity and speed? Or are navigators going to insist on an en-route aid of phenomenal precision, even when such exactness is of so little value?

Yours faithfully,

J. B. Parker.

1 Anderson, E. W., this Journal, Vol. 3, No. I, Jan. 1950, p. 61.

2 Astronomical Navigation in the Air, this Journal, Vol. 2, No. 4, Oct. 1949. 